\title{
COMPRAVENTA DE TIERRAS, CIRCULACIÓN MONETARIA Y SOCIEDAD CAMPESINA EN LOS SIGLOS X Y XI. \\ EL EJEMPLO DE GOLTRED DE REIXAC
}

VÍCTOR FARÍAS ZURITA

Universitat Pompeu Fabra

(Barcelona)

El tema del presente estudio será estudiar la circulación (la compraventa) de predios (bienes inmuebles), sobre todo $y$, específicamente, de tierras dedicadas al cultivo agrícola, los efectos que la circulación de tierras y monedas tuvieron sobre la sociedad campesina de los siglos X y XI. En diversos trabajos P. Bonnassie y J.M. Salrach se han esforzado por describir y explicar la lógica de esta circulación, bien reflejada en los documentos conservados por los pergaminos y cartularios de los archivos catalanes ${ }^{1}$. Nosotros quisiéramos prolongar estos esfuerzos analizando el tema en cuestión para un marco geográfico muy concreto: el territorium y la villa de Reixac, en el Vallès Occidental, una comarca del suroeste de la Catalunya Vella, integrada en el condado de Barcelona.

1. La condición para la realización de las compra-ventas (emptiones, comparationes) que estudiamos era la existencia de una práctica generalizada de considerar las immobilia como bienes alienables y de expresar el valor de

\footnotetext{
'P. Bonnassie, La Catalogne du milieu du Xe a la fin du XIe siècle. Croissance et mutations d'une société, 1, Toulouse, 1975, pp. 224-242; P. BONNASSIE, Une famille de la campagne barcelonaise et ses activités économiques aux alentours de l'An Mil, "Annales du Midi", 76 (1964), pp. 261-303; J. M. SALRACH, El mercado de la tierra en la economía campesina medieval. Datos de fuentes catalanas, "Hispania", 191 (1995), pp. 921-952.

"Anuario de Estudios Medievales", 29 (1999)
} 
los mismos con un equivalente monetario, o sea, de darles un precio ${ }^{2}$. La circulación de tierras presuponía, por lo tanto, el recurso a la moneda como medida de valor y como medio de cambio. En los siglos X y XI, esta práctica se hallaba firmemente implantada en los territorios analizados por nosotros (Reixac, Vallès). Incluso cuando se recurría al pago en especie (in rem valentem), este pago se expresaba de manera corriente en equivalentes monetarios (mancusadas, unciadas, dinaratas, solidatas).

2. Toda compra-venta de uno o más predios se llevaba a cabo respetando ciertos aspectos formales: 1) las compras se realizaban como transacciones que seguían normas legales específicas, sin duda, de origen romano y que implicaban la transferencia de la propiedad («proprietas, liberum è franchum alodium») del vendedor al comprador ${ }^{3}$;) toda transacción realizada sobre un bien inmueble quedaba fijada en un documento (charta, chartula) redactado sobre un pergamino y siguiendo un formulario relativamente fijo, seguramente de origen romano-visigótico ${ }^{4}$. Esta charta servía como título y prueba de la propiedad adquirida ${ }^{5}$. Cada charta detallaba los nombres del vendedor (vinditor) y del comprador (emptor); la naturaleza y el número de los bienes objeto de alienación; la localización de estos bienes; los lindes (affrontationes) de los mismos, su precio (precium) y la manera en que los mismos se habían adquirido («per comparacionem, de genitores, per decimum...»). El documento concluye con la datación de la compra-venta y las firmas (signa) de los vendedores, de los testigos del negocio (testes) y del escribano (scriptor) de la charta.

\footnotetext{
${ }^{2}$ Las fuentes no precisan los criterios que permitían fijar (adpreciare) un precio. Sin duda debía tratarse de múltiples criterios, diferentes para cada caso, como pueden ser la calidad del suelo, el tipo de cultivo al que se ha destinado una tierra, la necesidad que podía tener el vendedor de alienar la tierra... SaLraCh, Mercado, p. 927, ha escrito que «el conocimiento de las superficies junto con los precios, cuando esta asociación es posible ..., muestra proporciones y equivalencias, es decir, coherencia, lo que indica que las compra-ventas se rigen por pautas económicas de mercado". No obstante, indica la existencia de casos en los que "podemos sospechar que se trata de precios convencionales, arbitrarios, sin vínculo con la realidad económica". 209.

${ }^{3}$ Sobre la idea de proprietas que manejan las fuentes $c f$. BonNASSIE, Catalogne, pp. 205-

${ }^{4} C f$. E. Magnou-Nortier, La société läque et l'église dans la province ecclésiastique de Narbonne (zone cispyrénéene) de la fin du VIIIe a la fin du XIe siècle, Toulouse, 1976, pp. 14849 , que presenta detalladamente la "structure" de las "actes de vente entre particuliers".

${ }^{5}$ Bonnassie, Catalogne, pp. 206-208.
} 
3. Nuestra aproximación al tema anunciado se hará no sólo recurriendo a un territorio restringido sino también a un ejemplo concreto: el de Goltred, un habitante rural, un campesino sin duda, que entre finales del siglo X y principios del siglo XI vivió en Reixac del Vallès. Se trata de un ejemplo muy bien documentado gracias al hecho que los documentos relativos a este personaje se han transmitido, en su mayor parte, como copias incluidas en el segundo volumen del cartulario de la catedral de Barcelona, cartulario conocido como Libri Antiquitatum ${ }^{6}$. Los documentos en cuestión son en su mayoría compra-ventas y en su conjunto nos permiten estudiar cómo y de qué manera un habitante del ámbito rural incrementó su patrimonio gracias a la adquisición continua de predios ${ }^{7}$.

Comencemos por ver cuanto y cuando compró Goltred. Los cuadros que ofrecemos como anexos nos muestran que entre los años 986 y 1020 Goltred realizó un total de 76 compras en el territorio de Reixac; compras que se hicieron especialmente númerosas entre 996-1020: en estos 25 años realizó un total de 68 transacciones. Señalemos, sin embargo, que en dos ocasiones, concretamente en 987 y 994, Goltred compró tierras, respectivamente, junto a su padre y a su madre ${ }^{8}$. A partir de esta última fecha sólo aparecería Goltred como comprador de predios. En total adquirió más de un centenar de bienes inmuebles de diversa índole: terras, vineas, casas, hortos... La cifra exacta resulta imposible de determinar ya que en diversas ocasiones no se puede precisar el número de bienes afectados por la transacción ${ }^{9}$. Tengamos en cuenta, además, que hay que distinguir entre la compra de un bien determinado y la compra de derechos sobre un bien

${ }^{6}$ Los documentos referidos a Goltred y su familia, así como a otros habitantes de Reixac, se hallan en su mayor parte en el Liber II, fols. 178-230v. En cuanto a las fuentes utilizadas en este trabajo, proceden del Arxiu de la Catedral de Barcelona (ACB): Libri Antiquitatum (Lib. Ant.), y los pergaminos conservados allí mismo en el fondo Diversorum (Perg. Div.). Además hemos recurrido a los pergaminos de Cancelleria del Arxiu de la Corona d'Aragó (ACA/C), del Arxiu Històric de Terrassa (AHT) y de la Biblioteca de Catalunya (BC); al Cartulario de St. Cugat del Vallès (CSCV) editado por J. RIUS SERRA, Barcelona, 1945-1947; y a la edición que J. Alturo ha hecho de L'arxiu antic de Sta. Anna de Barcelona, Barcelona, 1985.

${ }^{7}$ Disponemos además de tres permutas realizadas por Goltred, que datan de 1003, 1008 y 1015. En lo que sigue se utilizará el término genérico 'tierras' como equivalente del término 'bienes inmuebles'; como tal el término engloba tanto las terras y los ortos, como las casas y las vineas.

${ }^{8}$ ACB, Lib. Ant., II, 570 (986); 617 (994).

${ }^{9}$ Un ejemplo: en 1014 Goltred compró «terras que sunt subtus Sci. Petri; in alio loco ipsas terras et ipso puio de Chagacans et ipsa chintana de Rexago; in alio loco, in villa Iudiga que vocant Tresculs ... ipsa terra cum ipsos glandiferos», ACB, Lib. Ant., II, 592 (1014). 
cuando la propiedad sobre el mismo estaba repartida entre diferentes propietarios, en la mayoría de los casos herederos. La compra se realizaba en estos casos como adquisición de los diferentes derechos («hereditates, voces, directos, porciones») que sobre un bien determinado tenían los diversos herederos. El precio pagado por cada una de las hereditates es normalmente muy bajo, casi irrisorio. En conjunto, tenemos noticias de que Goltred realizó diez compras de este tipo ${ }^{10}$.

Hecha esta advertencia, retengamos una primera evidencia: un núcleo familiar, por muy amplio que sea ${ }^{11}$, no podía trabajar directamente el inmenso conjunto de tierras que adquirió Goltred; más de un centenar si sólo tenemos en cuenta las compras; a ellas hay que añadir los bienes inmuebles que Goltred heredaría de sus padres y los que adquiriría fuera del territorio de Reixac. Por consiguiente, una buena parte de estas tierras debieron haberse cedido a terceros para que las trabajasen. Podemos suponer que se trataría de otros campesinos más modestos. ${ }^{12}$ Pero, ¿en qué condiciones se realizarían estas cesiones? ¿Mediante contratos? ¿Y a cambio de qué obligaciones? Las fuentes no nos dicen nada respecto a las relaciones contractuales que pudieron establecerse entre campesinos ${ }^{13}$. Se puede suponer, aunque con mucha cautela, que la cesión de las tierras se realizaría mediante un contrato de precaria; y que esta cesión implicaría el pago bien de censos en especie, bien de una tasa proporcional a la cosecha (tasca $)^{14}$.

\footnotetext{
${ }^{10} \mathrm{ACB}$, Lib. Ant., II, 533 (995); 574 (996); 658 (996); 576 (1002); 539 (1004); 524 (1006); Perg. Div.1.2, 1336 (1008) (Lib. Ant.. II, 577); Lib. Ant., II, 550 (1011); 618 (1013); 607 (1017).

"Sobre los miembros de los que se componía la familia de Goltred $c f$. infra apartado 8 .

12Opinión también de Bonnassie, Catalogne, 1, pp. 241 y 305.

${ }^{13}$ En su testamento Goltred deja una «pecia de vinea ... que laboravit Onofredo». Esta es la única referencia a una cesión de tierras a terceros por parte de Goltred.

${ }^{14} \mathrm{La}$ mayoría de los contratos de precaria del monasterio de St. Cugat en los territorios del Vallès se realizaron a cambio del pago de la tasca; $c f . C S C V, 35$ (954), 54 (957), 88 (967), 93 (970), 128 (978), 141 (981), 160 (984), 166 (985), 214 (988), 230 (988), 238 (989), 257 (990), 262 (991), 275 (992), 287 (992), 309 (995), 329 (997), 332 (998), 334 (998), 339 (998), 348 (1000), 403 (1006), 447 (1012), 487 (1022), 495 (1024); cf. además J. M. SALRACH, Formació, organització i defensa del domini de Sant Cugat en el segles X-XII, "Acta historica et archæologica mediævalia", 13 (1992), p. 139. La tasca representaba una onceava parte de la cosecha; $c f$. BONNASSIE, Catalogne, 1, pp. 253-524.
} 
Las mencionadas 76 compras realizadas por Goltred se centraban en el territorio de Reixac ${ }^{15}$, y aquí sobre todo en el llano que se extiende a ambos márgenes del río Besós, lo que hoy es el Pla d'Albinyana ${ }^{16}$ : ahí, in termino de Albiniana, fue donde Goltred efectuó un total de 41 compras ( $=54 \%$ del total de compras). Otra gran parte de compras se situaba en Ventenago: un total de 20 compras se refieren a la villa o al valle de Ventenago, zona de monte que, al parecer, formaba parte de lo que hoy es la Serra de St. Pere de Reixac ${ }^{17}$. Señalemos, finalmente, que junto a las númerosas compras realizadas en Reixac, sabemos que Goltred y su esposa, Ballomara, compraron algunas tierras en lugares tan distantes como Corró d'Amunt y Monteuges ${ }^{18}$. Es posible que sea Goltred de Reixac el que también aparece comprando bienes en Martorelles y Badalona ${ }^{19}$.

4. Abordemos ahora la cuestión de qué medios de pago fueron utilizados por Goltred y qué tipos de moneda. Nuestros cuadros y gráficos muestran, en primer lugar, la poca relevancia de las compras pagadas en especie (en total $5=7 \%$ ) frente a las compras pagadas en moneda o moneda/especie, que suman el $93 \%$ de todas las transacciones realizadas por Goltred. Curiosamente, las compras pagadas en especie aumentaron hacia el final de la vida de Goltred (volveremos sobre ello). Los datos relativos a Goltred evidencian, por lo tanto, una disponibilidad continua de moneda (liquidez). ¿Pero, con qué tipo de moneda pagó Goltred sus compras? Si dejamos de lado los sous (solidos), que eran una unidad de cuenta, Goltred

\footnotetext{
${ }^{15}$ Las fuentes refieren una villa de Rexago, denominada también villa Pasturanis o Pasturanicis o Tresculos; cf. ACB, Lib. Ant., II, 553 (924): «terminio de villa Pasturanicis que vocant Tresculos»; 559 (984): «terminio Pasturano que vocant Rexago». La villa Rexago abarcaba, entre otros, el «locum que dicunt valle Maiore», que parece localizarse hacia el sur del término, en las cercanías de la valle Carchara. otro topónimo vinculado al término de Reixac. of. CSCV, 338 (998); de este término también formaba parte el «locum que dicunt Porciano», situado al oeste del Besós, cf. CSCV. 397 (1005).

${ }^{16}$ No hay duda que se trata de la plana que se extiende desde la Serra de St. Pere de Reixac al este, hasta el margen derecho del Besós, y los límites de los antiguos términos de Ripollet (Palacio Auzido) y Barberà al oeste. El Pla d'Albinyana incorporaba también el término de Albolala (Ablada, Amblara), cf. ACB, Lib. Ant., II, 603 (997).

${ }^{17} \mathrm{La}$ villa de Ventenago se emplazaba en los límites de la villa de Rexago, $c f$. ACB, Lib. Ant., II, 680 (990): «in terminio de Pasturanis que vocant Rexago, intus in Ventenago"; 620 (1002): «intus in villa Rexago, in villa que vocant Ventenago»; AHT, Perg. I, 16 (1011): «in termino de Rexago, in villa Ventenago".

${ }^{18} \mathrm{ACB}$, Perg. Div.1.4, 59 (1021).

${ }^{19} \mathrm{ACB}$, Perg. Div.1.3, 54 (965); Lib. Ant., II, 551 (1013).
} 
pagó esencialmente con dos tipos monetarios: uno de metal plata y otro de metal oro. El tipo de plata eran los diners (denarios), propios del sistema monetario establecido por los monarcas carolingios. El tipo de oro eran los mancusos, y, en algunos casos, las uncias, propios del sistema monetario musulmán. Los mancusos eran el equivalente de los dinars musulmanes, y la documentación suele designarlos en ocasiones como mancusos iafaris y mancusos amuris ${ }^{20}$. Ambos equivalían a siete sous de plata, y son los únicos que circularon hasta aproximadamente $1030^{21}$. Los mancusos de Barcelona aún no aparecen en nuestra época. La uncia, por último, equivalía a siete mancusos o a (redondeado) cincuenta sous. La práctica totalidad de los diners que circularon en el condado de Barcelona procedían del taller instalado en la civitas homónima. Hasta 1017 aproximadamente eran las únicas monedas de plata que circularon en el condado. A partir de esta fecha aparecieron los solidos de diners grossos (solidos de moneta grossa) que equivalían a medio mancús o a 3,5 sous antiguos ${ }^{22}$. Las compras de Goltred pagadas en solidos de diners grossos datan una de 1017 (se trata, por cierto, de la primera mención de solidos de diners grossos para el condado de Barcelona), otras dos de 1018 y una de $1019^{23}$.

\footnotetext{
${ }^{20}$ Los mancusos iafaris, que aparecen en Barcelona hacia 990, eran el equivalente de los dinars dja'fari acuñados en Córdoba, donde dos hagib de al-Hakam II llevaban el nombre de Djafar. Los mancusos amuris circulaban al menos desde 993; probablemente se trate de monedas acuñadas bajo el gobierno de al-Mansur (Ibn abi Amir). A partir de 1001, aproximadamente, los mancusos iafaris eran conocidos también como mancusos vellos. $C f$. J. BOTET I Sisó, Les monedes catalanes, 1, Barcelona, 1908, pp. 28-31; M. CRUSAFONT I SABATER, Història de la moneda catalana. Interpretació $i$ criteris metodológics, Barcelona, 1996, pp. 60-64; G. C. MILES, The Coinage of the Umayyads of Spain, Nueva York, 1950, p. 59, 15; E. LEVI-PROVEnÇAL, Histoire de l'Espagne musulmane, 3, 255 y 259; BonNASSIE, Catalogne, 1, pp. 377-378.

${ }^{21}$ No existen dudas sobre el hecho que los mancusos que circularon en Catalunya eran efectivamente una moneda de oro, $c f$. Ph. GRIERSON, Carolingian Europe and the Arabs. The Myth of the Mancus, "Revue belge de philologie et d'histoire", 32 (1954), pp. 1059-1074; BONNASSIE, Catalogne, 1, pp. 376-79. Los documentos, por su parte, son muy explícitos en este sentido, cuando hablan de «mancusos de auro cocto, mancusos de auro bono placibiles, mancusos de auro cocto et optimo et legitime pensatos..."

${ }^{22}$ BonNASSIE, Catalogne, 1, pp. 386-89. Hay autores que, frente a BonNASSIE, han interpretado los "diners de moneta grossa" como una moneda de cuenta que se estableció a comienzos del siglo XI con la aparición de una moneda de vellón (denarium curribile); $c f . \mathrm{M}$. CRUSAFONT, Numismatica de la Corona catalano-aragonesa medieval (785-1516), Madrid, 1982, pp. 47-48.

${ }^{23} \mathrm{ACB}$, Lib. Ant., II, 581 (1017); 580 (1018); 605 (1018); 582 (1019).
} 
1. Las compras de Goltred: los medios de pago

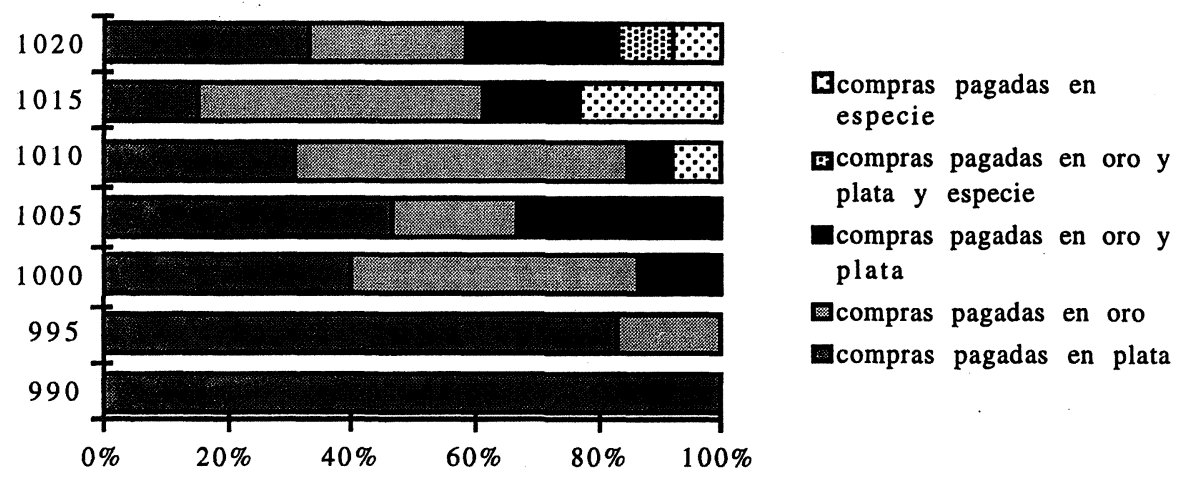

Constatados los diversos tipos de moneda utilizados por Goltred, hay que fijarse en la evolución que manifiesta el recurso a los diferentes tipos y en el ritmo de las transacciones. Sinteticemos lo que nos dicen al respecto nuestros cuadros y gráficos: Goltred realizó entre 986 y 1020 un total de 76 compras, por las que pagó un total de $1.456,5$ sous, lo cual es una suma ciertamente impresionante. El número de compras se hizo importante a partir de 996: de 8 compras realizadas entre 986 y 995 se pasó a 15 compras entre 996 y 1000 . Pero el valor monetario de éstas se incrementó ya a partir de 991 : de 28 sous entre 986 y 990 se pasó a 182,5 sous entre 991 y 995 , y a 277,5 sous entre 996 y 1000 . Entre los años $1001-$ 1005 el valor global de las compras experimentó un cierto retroceso, mientras se mantuvo el número de compras realizado por Goltred. Entre 1006 y 1010 se redujo el número de compras y también el valor global de las mismas, aunque la suma pagada no dejó de ser notable. Entre 1011 y 1020, el número de compras siguió la tendencia a la baja, al tiempo que las sumas pagadas se dispararon hasta alcanzar la cifra récord de 330,5 sous entre 1016-1020. 


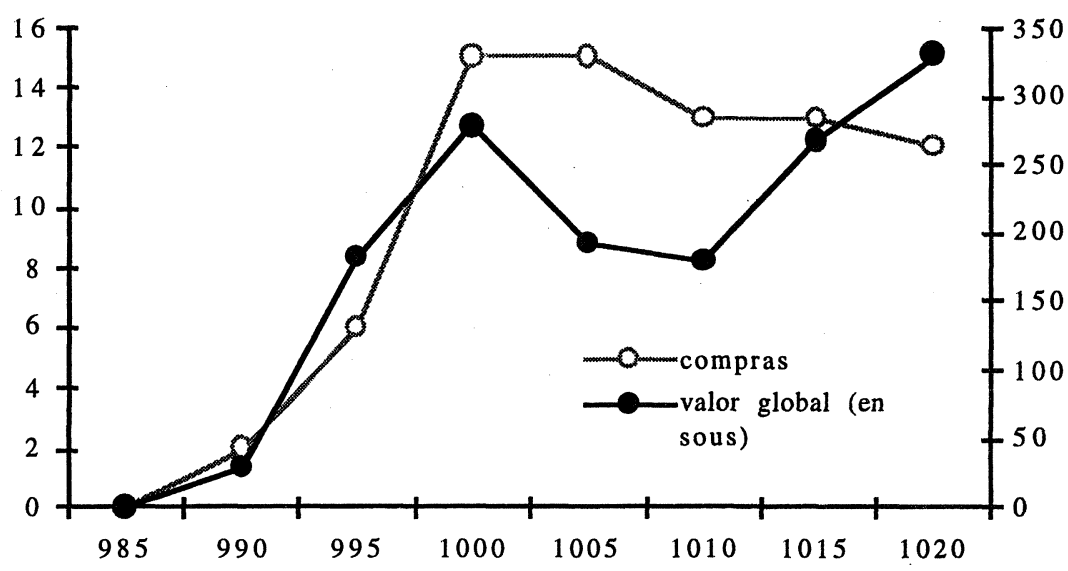

Este incremento fluctuante del gasto monetario frente a los años anteriores al 996 se vio, por otra parte, acompañado por la importancia cada vez mayor de la moneda de oro en las transacciones, hecho que puede observarse tomando como indicador la evolución que, de quinquenio a quinquenio, experimentó la proporción del valor global de las transacciones que se pagó en oro. Como puede verse en nuestros cuadros y gráficos, este porcentaje se disparó abruptamente a partir de 996. Esta disponibilidad de monedas por parte de Goltred no puede significar otra cosa que una entrada rápida y masiva de numerario oro en el territorio de Reixac a partir de dicha fecha. Transacciones realizadas en oro con anterioridad a 996 sólo hay una, por un valor de 1,5 mancusos. Después de 996 y hasta 1000 hay siete, por un valor total de 20,5 mancusos; y un 52\% del valor global de las compras pasó a pagarse en oro. Desde el año 1000 y hasta 1020, sin embargo, Goltred recurrió al oro en un total de 31 compras, invirtiendo en ello una suma equivalente a 115,5 mancusos. La proporción del valor contratado que se pagó en oro se situó entre el 75 y el $96 \%$. Es evidente, pues, que Goltred disponía desde el año 996 de abundante moneda de oro con la que pagar el número creciente de sus transacciones, número que a partir de 996 fluctuó entre las 12 y 15 compras por quinquenio. Nuestros cuadros muestran 
asimismo que esta entrada de oro era paralela al incremento del valor global de las transacciones, incremento que fluctua, pero con una clara tendencia al alza. Dicho de otra manera: Goltred recurría tanto más a la moneda de oro, cuanto más gastaba en sus compras de tierras.

3. Las compras de Goltred: la proporción del valor pagado en oro

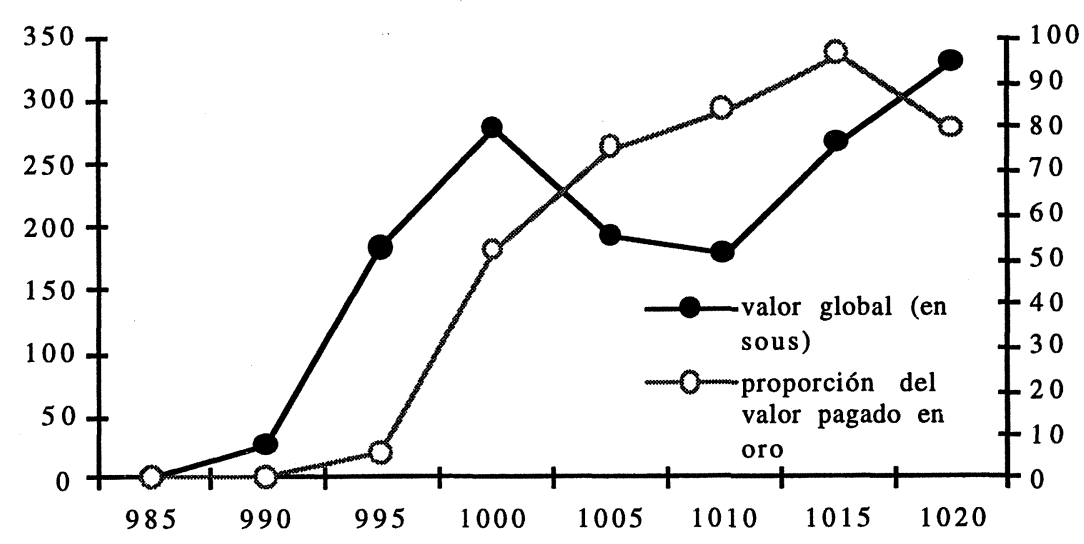

En contrapartida a esta importante difusión de la moneda de oro como medio de pago y medida de valor, el diner de plata, perdió importancia en la compra-venta de bienes inmuebles, aunque nunca desapareció del todo. Los denarios de moneta grossa, por otro lado, no desempeñaron sino un papel marginal y tardío en las transacciones de Goltred ${ }^{24}$.

5. Bonnassie ha demostrado la entrada masiva y la hegemonía de la moneda de oro en la economía catalana a partir de 980-990 aproximadamente, desplazando en gran medida a la moneda de plata en la compra-venta de bienes inmuebles. Los datos estadísticos elaborados por Bonnassie muestran

\footnotetext{
${ }^{24}$ Las compras pagadas con «solidos de diners grossos" son todas posteriores a 1016: Lib. Ant., II, 581 (1017); 580 (1018); 605 (1018); y 518 (1019).
} 
que se trata de un tendencia económica que se verifica a escala regional. Pero, con matices de importancia: fue muy temprana y fuerte en el Pla de Barcelona, seguido por el Vallès; pero, muy débil y más tardía en territorios como el Pla de Bages, en el condado de Manresa. Este numerario oro procedía en su totalidad de las cecas andalusíes. Su entrada masiva en la región conoció dos fases: entre $980-990$ procedía de las soldadas pagadas a los mercenarios catalanes al servicio de al-Mansur; a partir de 1010 el oro procedería de los pagos efectuados a los ejércitos catalanes por apoyar uno de los partidos que luchaban por el poder después de la caída del califato cordobés $(1008)^{25}$. Son, pues, hechos políticos los que explican el flujo de oro hacia Catalunya ${ }^{26}$, circunstancia que $M$. Barceló ha evidenciado con exactitud cuando escribe que «el proveïment de moneda d'or és ... estrictament correlatiu a la força de la feodalitat armada i a la vulnerabilitat política de la classe dominant andalusina $»^{27}$. No obstante, el impacto inmediato que tuvo este flujo sobre el territorium de Reixac fue de carácter, sobre todo, económico.

Bonnassie ha señalado la existencia de «sérieuses ponctions sur le pactole qui parvenait de Cordoue» por parte de los magnates catalanes. Pero, ha subrayado asimismo como hecho primordial el que «les mancusos se sont répandus trés rapidement, dans toutes les couches de la population ${ }^{28}$. A partir de la constatación de este hecho puede formularse la hipótesis de que la entrada del oro en la economía campesina hizo más dinámica la circulación de tierras, incrementando el número de compra-ventas y facilitando la concentración de bienes inmuebles en determinados casos. Como lo muestran claramente las estadísticas elaboradas por Bonnassie, el número y el valor

\footnotetext{
${ }^{25}$ Bonnassie, Catalogne, 1, pp. 343-351; 2, pp. 897-898; Crusafont I SABATER, Història, pp. $60-64$.

${ }^{26} \mathrm{G}$. FELIU I MONTFORT, Marca i passadís: els factors d'una expansió econòmica. "L’Avenç", 84 (1985), pp. 49-50, propone interpretar el flujo de oro hacia la región catalana como el resultado de una mejor relación entre el precio de la plata y el precio del oro en esta región que en el al-Andalus, lo que habría motivado simultáneamente un drenaje de plata (diners) hacia el sur y un drenaje de oro (mancusos) hacia el norte. La diferencia en la relación plata-oro y una rarefacción del numerario plata parecen haber existido efectivamente. Pero un flujo de oro tan importante hacia Catalunya como el que se registra a partir de 980 supondría, si se acepta la propuesta de Feliu, unos intercambios económicos regulares y considerables en su volumen. Precisamente éste es un hecho difícil de asumir.

${ }^{27}$ M. BARCELÓ, L'or d'al-Andalus circulant als comtats catalans entre 967 i 1100. Un or vist i no vist?, "Symposium numismático de Barcelona", 1, Barcelona, 1979, p. 314.

${ }^{28}$ Bonnassie, Catalogne, 1, p. 382.
} 
medio de las transacciones se multiplicaron a partir de 980 en el Pla de Barcelona, $y$, a partir de 990 , en el Vallès, paralelamente con el incremento de los pagos efectuados en oro. Fijémonos en el caso del Vallès, donde los datos de Bonnassie permiten observar 1) una entrada masiva de numerario oro a partir de 991 ; 2) un fuerte aumento del número de transacciones desde la misma fecha; y 3) un espectacular aumento del valor global de las transacciones y un incremento más modesto del valor medio de las transacciones. En definitiva, podemos decir que a partir del momento en que penetró el oro se compró más y más caro. Para volver al caso de nuestro protagonista, nuestros cuadros muestran que entre 996 y 1020 Goltred realizó 68 compras $=89 \%$ del total de compras, pagando un equivalente a 1.246 sous, de los que 955 sous fueron pagados en oro $=77 \%$. Si nos centramos en los quinquenios entre el año 1000 y el año 1020 la proporción del valor contratado en oro se eleva al $84 \%$ como media. No cabe duda, pues, que para Goltred la moneda de oro era la moneda por excelencia a la hora de adquirir nuevas tierras. La misma importancia de los pagos efectuados en moneda de oro se puede observar también en los cuadros relativos a las transacciones realizadas en el territorio de Reixac. (Las fluctuaciones que los cuadros referidos a Goltred y Reixac manifiestan con respecto al total de compras, al valor global y al valor medio de las mismas se pueden atribuir, indudablemente, a lo puntual de nuestra muestra. Si ésta fuera más amplia, no cabe duda que todos estos factores mostrarían una tendencia continua al alza. Las cifras reunidas por Bonnassie están ahí para demostrarlo).

Indiquemos, finalmente, que una de las mayores dificultades que podían aparecer en el contexto de una circulación de tierras sumamente dinámica era, que la masa monetaria se hiciera insuficiente: se trataba de un peligro ciertamente real, teniendo en cuenta que el numerario procedía en buena parte del exterior y que las transacciones eran cada vez más númerosas y de mayor valor (global) y que, por lo tanto, movilizaban un stock cada vez mayor de monedas. A ello hay que añadir una tendencia inflacionaria de los precios, constatada por Bonnassie tanto para el Vallès como para el Pla de Barcelona ${ }^{29}$. Una situación de insuficiencia monetaria fue, sin duda, la

\footnotetext{
${ }^{29}$ BonNASSIE, Catalogne, 1, p. 413: «a partir de la décennie 980-990, les prix connaissent une hausse très vive et sans précédent: ils doublent entre 980 et 1000 et doublent encore entre 1000 et 1020 environ». En cuarenta años, por lo tanto, los precios se cuadriplicaron por efectos de la inflación.
} 
que se produjo a partir de aproximadamente 1020, y ello explicaría el recurso de Goltred a los pagos en especie en los últimos años de su vida. El incremento de las compra-ventas saldadas parcial o enteramente en especie puede constatarse también a nivel regional ${ }^{30}$.

6. Pasemos al problema siguiente. ¿Cómo y dónde se han obtenido estas monedas de oro y plata con las que un campesino como Goltred compraba sus tierras? La pregunta no tiene fácil respuesta ya que las fuentes no nos dicen nada al respecto. No se puede descartar que en algunos casos los campesinos que participaban en las expediciones militares hacia alAndalus hayan vuelto con un botín y/o una soldada en monedas de oro $^{31}$. Pero, en la mayoría de los casos, creemos que las monedas se conseguían mediante la venta de productos agrícolas. Estos productos debían proceder esencialmente del trabajo de la familia campesina sobre sus tierras y de los ingresos en especie de los predios cedidos por un campesino a otro. La existencia de excedentes comercializables en el mundo campesino es un hecho subrayado por Bonnassie y para el que se disponen de suficientes pruebas documentales ${ }^{32}$. Por lo tanto, podemos suponer, en el caso concreto de Goltred, la existencia de excedentes ciertamente significativos, que permitieron regenerar continuamente las reservas monetarias que se invertían en la compra-venta de tierras.

Se plantea seguidamente la cuestión de dónde se vendían estos excedentes agrícolas. La existencia de mercados rurales en el Vallès no se puede documentar para los años anteriores al 1030-1050, aproximadamente. Las ventas de dichos productos debieron realizarse, por lo tanto, en el mercado urbano, esto es, en la ciudad de Barcelona, el tradicional centro mercantil y taller monetario del condado. Esta dependencia económica de las áreas rurales del condado respecto a la capital y su lugar de intercambio institucionalizado sólo cambiaría a partir de mediados del XI, aproximadamente, con la difusión de modestos centros urbanos en la comarca del Vallès. Estamos presuponiendo, por lo tanto, una forma de articulación entre ciudad y campo específica del siglo X y de la primera mitad del siglo XI,

\footnotetext{
${ }^{30}$ Proporciona una explicación de esta insuficiencia monetaria BonNASSIE, Catalogne, 1, pp. 389-398.

${ }^{31}$ Sobre la participación campesina en las expediciones militares públicas $c f$. BONNASSIE, Catalogne, 1, pp. 159 y 305-306.

${ }^{32}$ Bonnassie, Catalogne, 1, pp. 304-306.
} 
según la cual la ciudad de Barcelona desempeñaba el papel de centro de un intercambio institucionalizado para un elevado número de territorios del condado. Entre éstos el territorio de Reixac gozaba de una localización ciertamente ventajosa respecto a Barcelona: estaba situado a sólo unos trece kilómetros de la ciudad y estaba muy bien comunicado con la misma por la vía romana (la strata francischa o via calciata) que, siguiendo la cuenca del río Besós, llevaba hasta Barcelona.

Con relación tanto a Reixac como a los demás territorios rurales del condado, la antigua civitas, sede episcopal y residencia condal, cumplió, por lo tanto, hasta mediados del siglo XI, con dos funciones esenciales: 1) el mercado de la ciudad daba salida a los productos agrarios a cambio de monedas; 2) la ciudad proporcionaba los medios de pago porque disponía de un taller monetario y porque hacia ella fluía probablemente la masa del oro procedente del al-Andalus. En este sentido, Bonnassie ha mostrado cómo el recurso a los pagos en especie era tanto más frecuente, cuanto mayor era la distancia de una ciudad con taller monetario y mercado. Se explica así el gran número de transacciones pagadas en especie que se registran para una zona como el Pla de Bages hasta $1020^{33}$; por qué también, en esta zona el porcentaje de pagos en oro era, como media, seis veces inferior al porcentaje en el Pla de Barcelona: el núcleo urbano más cercano, Manresa, no disponía ni de taller monetario ni era un centro mercantil de primer orden, tampoco era, por último, un centro receptor de oro musulmán como podía ser la Barcelona condal y episcopal ${ }^{34}$. De ahí que en el Pla de Bages la circulación de tierras no llegó a tener nunca la dinámica que tuvo en el Pla de Barcelona y en el Vallès $s^{35}$.

En definitiva, podemos decir que una ciudad como Barcelona garantizaba un stock monetario a los territorios circundantes y creaba las condiciones para que este stock circulara y se infiltrara en estos territorios. En ambos sentidos la ciudad de Barcelona fue un factor importante, quizás una condición indispensable, para el desarrollo de una intensa circulación de

\footnotetext{
${ }^{33}$ El porcentaje de transacciones pagadas en especie fluctua en esta zona y de 970 a 1020 entre el 65 y el $92 \%$, cf. BONNASSIE, Catalognle. 2. p. 904

${ }^{34}$ BOnNASSIE, Catalogne, 1. pp. 395 y 390. Entre 970 y 1000 el porcentaje de transacciones pagadas en oro no supera el $2 \%$. En 1001-1010 representa un 9\%, y en 1011-1020 alcanza el $23 \%$.

${ }^{35} \mathrm{El}$ numero total de compra-ventas realizadas en el Pla de Bages registra un incremento continuo pero moderado entre 961 y 1020 . En el Vallès y en el Pla de Barcelona, por el contrario, lo que se observa es un incremento brusco del total de compra-ventas a partir de 980.
} 
tierras en su área de irradiación económica ${ }^{36}$. Ello se hizo especialmente palpable a partir del momento en que una masa considerable de monedas de oro comenzó a circular en el ámbito rural.

7. Todas las sociedades campesinas preindustriales conocen desigualdades en cuanto a los recursos económicos de los que respectivamente disponen los diferentes miembros que la componen. Un hecho que refleja estas desigualdades es la distribución de la tierra. Esta distribución se puede cuantificar, para nuestro caso y muy aproximadamente, gracias a las affrontationes. Cualquier transacción realizada sobre un bien inmueble indica los bienes que delimitaban aquel, así como los propietarios de dichos bienes. Esto nos permite, por un lado, determinar la proporción de propiedades campesinas en el territorio de Reixac, y, por otro, establecer las desigualdades en el seno del grupo de campesinos propietarios. Pues bien, contabilizando las affrontationes que aparecen en el conjunto de las compra-ventas conservadas para Reixac, se constata lo siguiente: una presencia aún significativa ( $20 \%$ de las affrontationes) de los establecimientos eclesiásticos, entre los que destacaban: 1) el monasterio benedictino de St. Cugat del Vallès, cuya implantación en el territorio de Reixac parece iniciarse gracias a una donación condal del año $988^{37}$; 2) la iglesia de St. Miquel de la ciudad de Barcelona ${ }^{38}$; y 3) la iglesia parroquial de St. Pere de Reixac. La

\footnotetext{
${ }^{36}$ El carácter, la intensidad y el radio de esta influencia en los siglos X y XI no ha sido, hasta ahora, objeto de un estudio sistemático. La recientemente publicada Historia de Barcelona, 2, La formació de la Barcelona medieval, Barcelona, 1992, por ejemplo, no toca apenas estos problemas. La mejor aproximación al problema puede hallarse en BONNASSIE, Famille, pp. 277288.

${ }^{37} \mathrm{CSCV}, 217$ (988): el conde Borrell concede a St. Cugat el «alodem meum proprium quod ego habeo in suburbio prelato, nomine et vocabulo Rixago", que le viene «ex propriis et racionabilibus adquisitis et profligacione iure debitis»; se trata de «terras et vineas, pratis, pascuis, aquis aqualibus, scopolis ac calculis, arduum et declivum, cultum et incultum». A partir de esta fecha se multiplican las adquisiciones (compras, permutas) de St. Cugat y de sus abades en el territorio de Reixac. Compras: CSCV. 224 (988); 241 (989); 305 (995); 318 (997); 397 (1005); 415 (1008); 416 (1008); 423 (1008); son compras del obispo-abad Ot las de 988, 997 y 1005. Permutas: CSCV, 233 (989); 242 (989); 248 (990); 256 (990); 270 (991); 306 (995); 338 (998); AHT, Perg. I, 12 (999); CSCV, 411 (1006). En el diploma del papa Silvestre II de 1002, CSCV, 382, se confirma a St. Cugat «ipsum alaudem de Resciaco cum terminis et suis adiacentiis, sicut Borrellus, comes, ibidem donavit»; la disposición se repite en el diploma expedido por Juan XVIII en $1007, C S C V, 412$, lo que demuestra la importancia de la donación condal para la implantación del monasterio en el territorio de Reixac.

${ }^{38} \mathrm{Se}$ trata de una de las iglesias parroquiales de la ciudad, cuya historia, como la de lạs demás iglesias parroquiales de la ciudad, no ha sido estudiada con detalle.
} 
presencia de magnates laicos (dos vicecomites, un vicarius) es irrelevante ${ }^{39}$, representando un $1 \%$ de las affrontationes. Lo que, sin embargo, importa retener es que casi el $80 \%$ de las tierras citadas en las affrontationes no pertenecía a ninguna de estas dos categorías. Con precauciones evidentes se las puede considerar como tierras de campesinos que las poseían en calidad de «liberum et franchum alodium» ${ }^{40}$. Por lo que se refiere a la distribución de la propiedad en el territorio de Reixac se puede afirmar, pues, que la gran masa de la propiedad inmobiliaria se componía de alodios campesinos. En ello nuestro territorio no se distinguía de los restantes territorios de la Catalunya Vella no pirenaica ${ }^{41}$. Citemos en este sentido los resultados de la encuesta hecha por Bonnassie para Montpeytà (en el Bages, cerca del actual St. Fruitós del Bages). Aquí el sector campesino representaba entre 981 y 1020 el $84 \%$. El sector de iglesias y clérigos el $15 \%$. Y el sector magnates el $1 \%$. Las cifras son, por lo tanto, comparables a las de Reixac.

Por otra parte, tanto los datos de Reixac como los de Montpeytà muestran que el mayor grupo de campesinos estaba formado por aquellos que se mencionan 1-10 veces en las affrontationes. En total representaban el $91 \%$ de los propietarios -el $93 \%$ en Montpeytà. De esta masa de pequeños campesinos alodiarios se destacaba un reducido grupo de campesinos

\footnotetext{
${ }^{39} \mathrm{ACB}$, Lib. Ant., II, 564 (1001): «vineas de Adalberto, vicecomite»; se trata de Adalbert, el hermano del vizconde Udalard de Barcelona, $c f$. S. SOBREQUÉs, Els barons de Catalunya, Barcelona, 1980. ACB, Lib. Ant., II, 524 (1006): «vinea de Guilielmus, vicecomite»; para la posible identificación de este vizconde $c f$. SOBREQUÉs, Barons, pp. 39 y 45 . ACB, Perg. Div. 1.2, 1336 (1008) (Lib. Ant., II, 577): «in terra de Domnucio, vicario»; probablemente se refiera al mismo la referencia contenida en Lib. Ant., II, 528 (996): «in terra de domno Donucio»; e vicario Donuç también era propietario de tierras en Martorelles, $c f$. Lib. Ant., III, 5 (1007) y Palau-solità, $c f$. BC, Perg. 2122 (1003). La presencia del conde en el territorio de Reixac se vio, sin duda, muy mermada por la donación de 988 a St. Cugat. Otras referencias a propiedades condales se refieren a bienes alienados del patrimonio condal: en 989 un tal Autemir vendió a St. Cugat una terra que había adquirido «per carta donationis quod mihi fecit Borrellus, comes»; cf. CSCV, 241. Por otra parte, los testamentos del sacerdote Barceló y de Goltred hacen referencia a tierras tenidas en el feo de Albiniana, lo que parece indicar que el conde continuaba conservando algunas posesiones en Reixac.

${ }^{40}$ Esta idea de un campesinado alodiario ampliamente implantado en la Catalunya Vella de los siglos X y XI ha sido defendida y desarrollada extensamente, sobre todo, por BONNASSIE. Recientemente esta idea ha sido cuestionada por historiadores como R. MARTí. L'alou a la documentació catalana d'època comtal: solució d'un problema historiogràfic genèric, "La vida medieval als dos vessants del Pirineu. Actes del 4t curs d'Arqueologia d'Andorra 1994". Andorra, 1997, pp. 28-60, y G. FELIU I MONFORT, La pagesia catalana abans de la feudalització, "Ánuario de Estudios Medievales", 26 (1996), pp. 19-41. No es este el lugar para presentar y valorar las propuestas alternativas de estos historiadores. Es de esperar que ello pueda realizarse en el marco de un futuro debate historiográfico.
}

${ }^{41} \mathrm{Cf}$. Bonnassie, Catalogne, 1, pp. 224-36. 
acomodados, propietarios de un considerable número de bienes inmuebles que, al menos en parte, no trabajaban por sí mismos. Se trataría de todos aquellos que se mencionan más de 10 veces en las affrontationes. En la villa de Reixac este grupo representaba el 9\%, y en Montpeytà el 7\% del total de la población de campesinos alodiarios. Para Reixac podemos mencionar, como pertenecientes a este grupo, además de a Goltred, a Bonfill, Igiga, femina, Izaide, Lobaton, Richell, Seniofred, Sunyer, Trasoarius y Truitell. También a éstos los vemos comprando tierras en Reixac, aunque no con la insistencia de Goltred: Trasoarius, por ejemplo, realizaba dos compras en 996, una en 997, dos en el año 1000 y una en $1007^{42}$. Por todas ellas pagaría un total de casi 12 mancusos y 19 sous, más diversas cantidades de cereal. A otros integrantes de este grupo se les puede documentar como vendedores de tierras. Truitell, la concubina del sacerdote Barceló, por ejemplo, vendió tierras a Goltred en 997 y 1017, por un total de 14 sous $^{43}$. Fue este estrato de campesinos el que debió beneficiarse mayormente de la súbita y masiva entrada del numerario oro y del dinamismo de la circulación de tierras que caracterizó las décadas entre 990 y 1020. Se constata, pues, una correlación positiva entre la disposición de numerario oro (y plata) y la frecuencia con la que un individuo es mencionado en las affrontationes. Dicho de otra manera: la desigual distribución de la propiedad entre la población campesina de un territorio se refleja en una desigual participación en las compra-ventas y la acumulación de tierras. El hecho que sólo los campesinos acomodados pueden comprar de manera sistemática resulta evidente, sobre todo, para el caso de Goltred, cuyo nombre se menciona un centenar veces en las affrontationes de las compraventas realizadas en Reixac. En su conjunto, sin embargo, este estrato no abarcaría nunca más que una pequeña minoría de familias e individuos «dont le train de vie n'est pas sans approcher -et depasser sans doute parfoiscelui de l'aristocratie» (Bonnassie).

Sorprendentemente la comparación de los datos de Reixac con los de Montpeytà muestra que la incidencia del boom de los años 990-1020 no modificaría sensiblemente este hecho: el número de campesinos acomodados no muestra diferencia entre un territorio profundamente afectado por el

\footnotetext{
${ }^{42}$ AHT, Perg. I, 8 (996); 11 (997); ACB, Lib. Ant., II, 710 (1000); 600 (1000); AHT, Perg. I, 15 (1007).

${ }^{43} \mathrm{ACB}$, Perg. Div. 1.2, 1342 (997) (Lib. Ant., II, 601); Lib. Ant., II, 607 (1017).
} 
impacto de una muy dinámica circulación de tierras - Reixac- y un territorio en el que la circulación de tierras no sobrepasó nunca una intensidad mediocre - Montpeytà-. Más que incrementar el número de campesinos acomodados, lo que se produjo en Reixac fue un distanciamiento entre este estrato y el estrato de campesinos menos favorecidos. El caso de Goltred es en este sentido un ejemplo extremo ${ }^{44}$.

8. La historia de la familia de Goltred, nos muestra que al menos una parte de las familias de campesinos acomodados partían ya con ventaja en el momento que se iniciaba el boom de 990-1020 y antes que el oro musulmán viniera a vivier l'économie de base (Bonnassie). Sabemos que Goltred nació en una familia que ya disponía de importantes recursos antes de que él iniciara sus compras de tierras. Una reparación de escrituras perdidas durante el ataque de al-Mansur a Barcelona nos proporciona noticias acerca de compras de tierras hechas por Blandino y Chindeleva, los padres de Goltred. En este documento se refieren más de una docena de tierras y dos viñas, todo ello situado en el terminium de Reixac ${ }^{45}$. Por lo que nos dice el documento estas terras y vineas fueron compradas por Blandino y Chindeleva conjuntamente a diversos personajes, aunque no se hace referencia al precio pagado por estos bienes. A la muerte de Blandino, estos bienes pasaron a Chindeleva, la cual «ea abuit et tenuit cum filios suos in plenissima dominacione»

Goltred pertenecía a una familia de status destacado en el ámbito de Reixac. Su tío Barceló era presbiter, posiblemente de St. Pere de Reixac. Este mismo Barceló también era, junto a su concubina Truitell, un importante propietario de tierras ${ }^{46}$. Podemos hacernos una idea aproximada de lo

\footnotetext{
${ }^{44}$ Ejemplos de campesinos del condado de Barcelona que participan activamente en la compra-venta de tierras han sido apuntados por G. FELIU, Las ventas con pago en moneda en el condado de Barcelona hasta el año 1010, "Cuadernos de Historia Económica de Cataluña", 5 (1971), p. 40; para un estudio centrado en una familia de campesinos acomodados cf. BONNASSIE, Famille, pp. 261-303.

${ }^{15} \mathrm{ACB}$, Lib. Ant., II, 518 (994). Los bienes que se mencionan son los siguientes: una pieza de terra en Ventenago, piezas de terra en la sierra de Reixac, una fexa de terra en Perella, Reixac, dos vineas y una fexa en Val Carcara, tres piezas de terra en Albiniana, un campo en Albolala, un quadro de terre en Ruvira, dos piezas terre en Val Maiore y una terra en Romanello.

${ }^{46}$ Barceló es mencionado cuatro veces en las affrontationes; Truitell doce veces.
} 
que fue el patrimonio de este sacerdote rural, gracias a su testamento ${ }^{47}$. En éste dejaba a St. Pere de Reixac sus casas, junto a un ortale con arbores. A St. Cugat dejaba unas terras. Su concubina Truitell recibía la mitad de unas casas, ortos y terras en Ventenago y Ripollet, la mitad de unas viñas en Albinyana, además de paños, herramientas (exada $I$, podadora $I$ ) y un ternero (vitello I moreno). A sus hijos dejaba la otra mitad de los bienes que recibía Truitell, un huerto, unos casales, una vaca y un asno, herramientas y recipientes diversos («cubos II, exada I, cavago I, podadora I, dextrale I, tribanos II, sira I, scrinio I, parilios II de portaduras, bariles II»). Su nepos Goltred recibía una casa con curte, orto y arbores, que habían sido del padre de Barceló, Lupo. A una tal Gontelle mandaba dar su gato blanco; pro anima sua ordenaba vender su caballo, seis ovejas, seis cerdos y un asno; finalmente mandaba que fueran pagadas todas las deudas que había contraído en vida.

La propia familia de Goltred se componía de su esposa Balloma$r a^{48}$, de sus cuatro hijos Bernat, Ermengoll, Ramon y Mir; y de sus cuatro hijas Blancucia, Engucia, Adalaidis, Trudgardis. Como ya hemos dicho, los padres de Goltred eran Blandino y Chindeleva. Es posible que el sacerdote Barceló haya sido el hermano de Blandino. Si ello es correcto, sabriamos que el abuelo paterno de Goltred fue un tal Lupo, ya que éste nos consta como padre de Barceló. De Goltred sabemos que murió a finales de enero de 1022 , a una edad que podemos estimar en torno a los $55 \mathrm{años}^{49}$. Su esposa Ballomara le sobreviviría muchos años y no moriría hasta abril de $1044^{50}$.

\footnotetext{
${ }^{47} \mathrm{ACB}$, Lib. Ant., II, 549 (992) (A. M. UdINA ABELLó, La successió testada a la Catalunya altomedieval, Barcelona, 1984, ap. 39).

${ }^{48}$ La primera referencia al matrimonio Goltred y Ballomara data de 997 cuando ambos, junto a la madre de Goltred, Chindeleva, venden al obispo-abad Ot de Sant Cugat sus hereditates en tres piezas de tierra.

${ }^{49} \mathrm{El}$ testamento de Goltred, ACB, Lib. Ant., II, 675 (UdINA ABELLÓ, Successió. ap. 119), está datado las II kalendas de febrero del año vigésimosexto del reinado de Roberto. Aparentemente se trata de un error del copista, ya que la publicación sacramental del testamento (Lib. Ant., II, 703; UdINA ABELLÓ, Successió, ap. 120) dice que éste fue dictado las V kalendas februarias. Pero la fecha de esta publicación sacramental tampoco es del todo segura: el documento se fecha las II kalendas de febrero del citado año; sin embargo, hay una donación hecha remedium anime por los manusmissores de Goltred las III kalendas de febrero, o sea, un día antes de dicha publicación sacramental; $c f$. Lib. Ant., II, 693.

${ }^{50} \mathrm{ACB}$, Lib. Ant., III, 645: publicación sacramental del testamento de Ballomara, fechada el 27 de abril de 1044, donde se dice que ésta murió el mismo mes de abril.
} 
¿En qué consistían las recursos económicos de esta familia? En su testamento Goltred dejaba los siguientes bienes muebles: 1) recursos monetarios: «mancosada I de diners limoganos» (diners de Limoges, ¿sobrantes de una peregrinación al santuario de Le Puy?); 2) ganado: «bestias quam de minutas vel grossas, ovelgas, cabras, porcos, pullino chavallino», una equa y su filia; 3 ) reservas agrícolas: «pane et vino ... tam de vetere quam de novo»; 4) recipientes para el almacenamiento del vino y del mosto: «cubos, tonnas, vascula maiore vel minore»; 5) drapos. Pero, la parte más importante de sus riquezas la constituían las tierras, cuyo número Goltred fue incrementando sistemáticamente durante su vida, tal como nos informan las compra-ventas de las que se han conservado la noticia. Sorprendentemente su testamento apenas da cuenta de estas tierras de manera explícita $^{51}$. Más adelante intentaremos explicar este hecho. Por ahora centrémonos en la descripción del patrimonio inmobiliario de Goltred ${ }^{52}$.

Según las compras que realizó, este patrimonio consistía, sobre todo, en terras, término ambiguo, pero que en la mayoría de los casos designaría tierras de labor, en ocasiones provistas de $\operatorname{regos}^{53}$. Algunas de

\footnotetext{
${ }^{51}$ Los bienes inmuebles mencionados en el testamento son: "pecia I de vinealo ... ad ipsas Fexas", que lega a St. Miquel de Barcelona; "pecia I de vinea ... que est in ipso feo de Albinana», que deja a St. Cugat; terras vel vineas y "fexa I de terra qui est in Albignano" que lega a sus hijas Blancucia y Engucia; "semodiata I de terra" que deja a su hija Blancucia. Una parte de las tierras que dejaba a éstas ya les habían sido donadas como hereditas el dia de su matrimonio.

${ }^{52}$ Señalemos que el que compraba era siempre Goltred (excepción hecha de dos compras tempranas hechas con su padre y su madre, respectivamente). La mujer de Goltred. Ballomara, no compró nunca en vida de Goltred, ni aparece junto a su esposo comprando, excepción hecha de una compra realizada en 1021, cf. ACB, Perg. Div. 1.4, 59. Lo corriente es que en las chartas catalanas de nuestra época marido y mujer aparezcan conjuntamente como compradores. Incluso después de la muerte de Goltred, en 1022, Ballomara aparece como compradora una sola vez (junto a sus hijos Mir y Bernat) y como vendedora también una sola vez, aunque en ambos casos los que respectivamente venden y compran son sus propios hijos Bella y Mir; $c f$ ACB, Lib. Ant., II, 660, (1026); Lib. Ant., II, 646 (1029). No he podido dar con una explicación plausible para el hecho que Ballomara prácticamente no aparezca como compradora o vendedora ni antes ni después de la muerte de su marido. Las disposiciones testamentarias de Ballomara, $c f$. Lib. Ant., III, 645 (1044), no hacen referencia a bienes inmobiliarios propiedad de ella. Tan sólo deja a su hijo Mir el directum que tenía en vida in casas, in terras, in vineas et in arboribus. El resto de sus legados consiste en diversas cantidades de cereal y vino, un numero indeterminado de cabezas de ganado (ovejas, cabras, cerdos), una tonna y un cubo. A remarcar la ausencia de legados en moneda.

${ }^{53} \mathrm{ACB}$, Lib. Ant., II, 574 (996): "pecias II de terra subtus regariam cum pomiferis"; 558 (997): "terra super rego et subtus rego"; 711 (1003): "terra subreganea cum arboribus vel pomiferis et vides"; 547 (1008): "regos et capud regos que ad rigandum apertinet ad ipsas II sortes de terra".
} 
estas terras se dedicaban al prado ${ }^{54}$. Otra gran parte del patrimonio de Goltred consistía en tierras dedicadas al cultivo vitícola. Las vineas aparecen en 21 de las 76 compras hechas en Reixac. Goltred también compró huertos, a menudo irrigados ${ }^{55}$; en 1007 compraba derechos de agua para regar uno de sus huertos, así como dos matas de ulliastros situados junto a un canal de regadío ${ }^{56}$. Todas estas diferentes parcelas estaban provistas frecuentemente de $\operatorname{arbores}^{57}$, entre los que se citan: «pomiferos, ficulneas, perarias, glandiferos, olivas ${ }^{58}$. En once ocasiones Goltred compró casas provistas de tierras y terrenos adyacentes («curtes, closuras, ortos»), lugares de almacenamiento (cigias) y una prensa (torculario) ${ }^{59}$. Remarquemos, por último, la adquisición de tierras de bosque y monte. En 1015 Goltred compraba a Trasoario y Guisla una quinta parte «in ipso nostro monte vel in nostro bosco» incluyendo «ipso pasquer qui inde exit», por cuatro «uncias in rem valentem ${ }^{60}$; lo que aquí se compraba no eran sólo las tierras de bosque, sino también el censo (pascuarium) cobrado a aquellos que aprovechaban los recursos de este bosque para la pastura. El interés de Goltred por adquirir tierras de yermo, garrigas o bosque se manifiesta también en otras dos compras, realizadas ambas en $1017^{61}$. Tanto la compra de 1015 como las de 1017 se localizaban en la zona montuosa de la villa Ventenago.

${ }^{54} \mathrm{ACB}$, Lib. Ant., II, 609 (1002): «ipsa terra cum ipso prad».

${ }^{55} \mathrm{ACB}$, Lib. Ant., II, 620 (1002): «ortos ... subreganeos ... cum arboribus et pomiferis et aurundines"; 584 (1008): "petia I de orto cum arbores et pomiferos et glandiferos et salices et vides ... cum rego et fonte que ad regandum apertinet ad ipso orto»: 621 (1011): "orto ... super rego et subtus rego cum arboribus et pomiferis».

${ }^{56}$ ACB. Perg. Div. 1.1, 2395 (1007) (Lib. Ant., II, 656): «aqua que tu rigare possis tuo horto, cum rego et per rego dure posis hubi volueris, et alio loco matas II de huliastros».

${ }^{57}$ ACB, Lib. Ant. II, 597 (1003) «terras et vineas cultas et ermas et arboribus fructuosis et infructuosis»; 539 (1004): «terra cum arboribus ... vinea cum ipso pomifero»; 592 (1014): "terras cultas et ermas cum arboribus et pomiferis et glandiferis".

${ }^{58} \mathrm{ACB}$, Lib. Ant., II, 529 (1002): «petia I de terra cum ficulneas et perarias et glandiferos qui ibidem sunt»; 557 (1012): olivas.

${ }^{59} \mathrm{ACB}$, Lib. Ant., II, 530 (994): «casa et curte et terra ... et closuras et torculario ... cum ipsa cigia et ipsa tornelle qui ibidem est": 558 (997): "casas ... et curte cum ciges et terra cum arboribus vel pomiferis et vides, et in alio loco una terra cum arboribus vel glandiferis»: 627 (1004); 596 (1008); 547 (1008).

${ }^{60} \mathrm{ACB}$, Lib. Ant., II, 653 (1015): «in ipso nostro monte vel in nostro bosco ipsa quinta parte ... sic vindimus tibi ipsam quintam partem in terra, in roveres, in elzinas, in ligna, in glande vel in ipso pasquer qui inde exit».

${ }^{61} \mathrm{ACB}$, Lib. Ant., II. 581 (1017): «terra culta et erma el garriga et ligna et lapides»: 541 (1017): «terra cum ipso boscho». 
Por lo que se refiere a la condición social de los vendedores, poco es lo que podemos decir al respecto. Por un lado podía tratarse de los propios familiares de Goltred. Este es el caso de su hermana Bella, probablemente una viuda (quizás desde ca. 1009) ${ }^{62}$, madre de una hija de nombre Urucia. Las ventas a favor de Goltred datan de 994 (30 sous), 996 (18 sous), 1001 (1 mancús), 1002 (1 sou), 1004 (1 mancús, 8 sous) y 1006 $(5 \text { sous })^{63}$. La suma total pagada por estas compras se eleva a 2 mancusos, 62 sous $=76$ sous. En la mayoría de las ocasiones, cuatro sobre seis, se trataba de la venta de la hereditas por parte de Bella ${ }^{64}$. En este sentido lo que parecía estar haciendo Goltred era recuperar para sí los bienes paternales que había heredado su hermana. Por otra parte, y como ya hemos constatado, en diversas ocasiones eran otros campesinos acomodados los que vendían tierras a Goltred. Sin embargo, podemos suponer que la mayoría de los vendedores debieron ser campesinos menos favorecidos que Goltred. Ello lo sugieren aquellos casos en que Goltred se aprovechaba de vendedores que se hallaban en dificultades: así, en 1009 Nevolenda y sus hijas Guilierada y Filmera le vendían por siete sous una pieza de tierra «per nutrimentum de filiis et de fratribus nostris aliis minoribus». En 1017 Speciosa, femina, y su hijo Bonushomo le vendían una tierra por un mancús y cuatro «sous de denarios pro ipsa necessitate qui fuit in ipso anno q[uando] homines exierunt de comitato Barchinona et fuerunt in alias regiones». Nos hallamos aquí ante el conocido caso de un campesino rico que aprovechaba las dificultades económicas de familias campesinas que atravesaban un período crítico o que se habían visto perjudicadas por un año de malas cosechas.

Señalemos, por último, que la acumulación de bienes inmuebles emprendida por Goltred se realizó esencialmente por la via de las compras.

\footnotetext{
${ }^{62}$ Para 1006 se documenta un matrimonio Guifré y Bella, aunque no es seguro que ésta sea la hermana de Goltred. Sabemos, por otra parte, que Bella era madre de una tal Uristia, $c f$. ACB, Lib. Ant., II, 568 (1009); en este documento se hace referencia a la ereditate paterna de Urucia que había sido menguada por Goltred y Blandino, el padre de éste y de Bellano. Ello parece indicar que el padre de Urucia habría muerto antes que su abuelo, Blandino, cuya muerte debió producirse entre 992 y 994.

${ }^{63}$ ACB, Lib. Ant., II, 530 (994); 658 (996); Perg. Div.1.1, 2136 (1001); Lib. Ant., II, 576 (1002); 539 (1004); 524 (1006). Sólo el primero de estos documentos nos dice expresamente que Bella es la hermana de Goltred; pero todo hace pensar que ésta y la Bella de los otros documentos son una y la misma persona. Añadamos que en 997 hay una venta hecha por una Bella a una tal Chindeleva: sin duda se trata de la Bella ya citada y de su madre Chindeleva; Lib. Ant., II, 588.

${ }^{64}$ Bella indica siempre que los bienes o derechos que vende le vienen «de genitori meo», esto es, de su padre, Blandino.
} 
En este sentido cabe indicar los escasos testimonios de préstamos o impignorationes que podrían haber constituido un medio eficaz para acaparar tierras: Goltred sólo realizó una, en 1011, significativamente, por siete sesters y una emina de cebada ${ }^{65}$. Los préstamos no parecen haber sido un medio frecuentemente utilizado por campesinos que disponían de recursos monetarios para acumular bienes inmuebles; por lo tanto, podemos suponer que el endeudamiento no fue un factor que haya incidido decisivamente en la estratificación campesina, esto es al menos lo que podemos deducir del caso concreto de Goltred.

9. Acumulación significa, en términos sociales, promoción de un estrato reducido de campesinos acomodados; significa, por tanto, estratificación, en el sentido que un pequeño grupo de campesinos se distancia por la cantidad de sus recursos económicos (tierras, monedas) del resto de campesinos menos favorecidos. Es esta estratificación la que permitiría el acercamiento o el acceso de estos «grands rassembleurs de terres» (Bonnassie) a las élites de la sociedad ${ }^{66}$. En el caso de Goltred, este hecho puede estudiarse muy bien a través del destino de sus hijos.

Ramon al parecer no estuvo casado ni tuvo hijos, esto al menos es lo que indica la publicación sacramental de su testamento, datada el primero de agosto de $1036^{67}$. Según ésta, Ramon había muerto en febrero y dejaba un total de ocho mancusos que serían pagados de su hereditas. Esta hereditas parece haber estado empeñada, ya que Ramon autorizaba a sus hermanos Mir y Bernat y a su madre Ballomara redimirla. A su hermano Ermengoll concedía un caballo, un escudo y una espada. Su hermano Bernat, por lo que se deduce de su testamento, no estuvo casado ni tuvo hijos ${ }^{68}$. Sabemos que murió en mayo de $1037^{69}$, legando una parte de sus hereditates a St. Cugat. Pero la mayor parte de estas hereditates pasaban a sus hermanos Mir, Ermengoll, Trudgardis y Engucia. El total de los legados en moneda ascendía a quince mancusos. Entre los bienes testados destacaban además un

\footnotetext{
${ }^{65}$ ACB, Lib. Ant., II, 589 (1011).

${ }^{66}$ Para este hecho $c f$. también BonNASSIE, Famille, pp. 270-297.

${ }^{67}$ ACB, Lib. Ant., II, 690 (1036).

${ }^{68} \mathrm{ACB}$, Lib. Ant., II, 644 (1037). de 1037.

${ }^{69} \mathrm{ACB}$, Lib. Ant., II, 699: publicación sacramental del testamento datada el 11 de agosto
} 
caballo, dos espadas, una lanza y un alsbergo. Tanto Ramon como Bernat disponían, por lo tanto, de un equipamiento militar más o menos completo. Lo cual, a su vez, sugiere su pertenencia a un sector destacado de la población campesina, en el sentido que podían darse el lujo de adquirir armas y caballo, y de combinar la vida campesina con la actividad guerre$\mathrm{ra}^{70}$. Llama además la atención que ambos hermanos eran solteros y que su respectivo patrimonio, compuesto esencialmente por sus hereditates, no parece haber sido algo fuera de lo común. Sin duda los compensaba la guerra. Se podría pensar que ambos habían sido los hijos menos favorecidos por la herencia paterna, y que no les habría quedado otra alternativa que buscar su sustento en el servicio militar.

Cuando en 1044 moría Ballomara, la viuda de Goltred, le quedaban sus hijos Mir y Ermengoll, y sus hijas Engucia, Trudgardis y Adalaidis ${ }^{71}$. De Ermengoll sabemos lamentablemente muy poco. Ignoramos si estuvo casado y si tenía hijos. En 1044 lo vemos comprando dos piezas de terra en Reixac por las que pagó un sou y medio. Las affrontationes que se dan para estas terras permiten constatar que poseía otras tierras junto a las que compraba. En 1067 Ermengoll recibía de su hermana Trudgardis un préstamo de catorce mancusos de Barcelona, por lo que le empeñaba una pieza de terra $^{72}$. El mismo año Ermengoll vendía a Trudgardis una pieza de terra por cuatro mancusos de Barcelona ${ }^{73}$. Pero Trudgardis no sólo compraba tierras a sus hermanos: así, en 1068 la vemos adquirir a una tal Teduira y a su hijo Guerau una semodiata de viña en Reixac por un mancús y medio ${ }^{74}$. De Trudgardis sabemos, además, que estaba casada con un tal Balluvino, matrimonio que al parecer disfrutaba de una desahogada situación económica. Más tarde esto tendría su reflejo social. El hijo de ambos, llamado Mir Balluvino, consta desde 1091 como canónigo catedralicio ${ }^{75}$. He aquí, por lo tanto, que un nieto de Goltred abandonaba definitivamente

\footnotetext{
${ }^{70}$ Bonnassie, Catalogne, 1, pp. 305-306.

${ }^{71}$ Engucia está documentada en 1047, cf. ACB, Lib. Ant., II, 649, y en 1055 junto su marido, cuyo nombre ignoramos. Trudgardis y Adalaidis aún vivían en 1067, cf. Lib. Ant., II 642 y 695: este último documento es una venta de una terra realizada por Adalaidis a favor de Trudgardis a cambio de cuatro mancusos de Barcelona.

${ }^{72} \mathrm{ACB}, \mathrm{Lib}$, Ant., II, 642.

${ }^{73}$ ACB, Lib. Ant., II, 668

${ }^{74} \mathrm{ACB}$, Lib. Ant., II, 707

${ }^{75}$ ACB, Lib. Ant., I, 824; 791.
} 
el mundo al que habían pertenecido sus antepasados para pasar a formar parte de las élites de la sociedad. Pero Mir Balluvino no fue el primero en dar este salto: unos cuantos años antes le había precedido en la experiencia su tío Mir Goltred.

10. A pesar de la evidente promoción social experimentada por la familia de Goltred la mayoría de sus hijos continuaban perteneciendo en el fondo al mundo campesino. Ramon y Bernat eran más que nada guerreroscampesinos, y, los demás, campesinos con fortunas más o menos considerables. La única excepción de esta continuidad familiar la representaba el que era probablemente uno de los hijos más jóvenes de Goltred: Mir Goltred. Gracias a la riqueza y el estatus alcanzado, Goltred logró situar a Mir Goltred como canónigo del capítulo catedralício de Barcelona, lo que no deja de ser un logro considerable, considerando que el capítulo era una comunidad que se reclutaba preferentemente entre las élites aristocráticas. Los contactos, por otra parte, entre la familia de Goltred y la catedral databan al menos desde 994. Aquel año Goltred y su madre acudían a Bonushomo, iudex y levita de la catedral, para reparar una serie de escrituras que se habían perdido durante el ataque a Barcelona ${ }^{76}$.

El hijo de Goltred suele aparecer en la documentación de la catedral como Miro Goltredi, levita o sacer. Como levita constaba ya en $1020^{77}$. Sabemos que desde 1054 al menos era sacerdote. ${ }^{78}$ La última referencia a Mir Goltred como levita data del año $1052 .{ }^{79}$ Ello quiere decir que su ordenación sacerdotal se debió producir entre 1052 y 1054 . Parece ser que su cargo en el capítulo era el de llevar el hospital. Como procurator

\footnotetext{
${ }^{76} \mathrm{ACB}$, Lib. Ant., II, 518 (994). El acto se llevó a cabo en la iglesia de St. Pere de Reixac. Llama la atención que Blandino y Chindeleva guardaran al menos una parte de sus documentos en Barcelona: «ipsas predictas cartulas in Barchinona eas misit» (Blandino) et «ibidem eas perdidit ubi postmodum non eas invenit". Ignoramos dónde y quién guardaba las cartulas en cuestión. Para el citado levita Bonushomo $c f$. F. VALLS-TABERNER, El Liber iudicium popularis, de Homobonus de Barcelona, en F. VALLS-TABERNER, Obras selectas, 2, 235-246.

${ }^{77}$ Un Miro, levita aparece en un documento del 18 de enero de 1020, cf. ACB, Lib. Ant., III, 370. La primera referencia segura a que Mir Goltred era levita data del 1026, $c f$. Lib. Ant., III, 660 .

${ }^{78} \mathrm{ACB}, \mathrm{Lib}$. Ant., II, 651; 636. En nuestra documentación aparece otro canónigo llamado Mir. Pero éste ya era presbiter cuando Mir Goltred aún era levita; $c f$., por ejemplo, Lib. Ant., I, 532 (1048).

${ }^{79} \mathrm{ACB}$, Lib. Ant., II, 563.
} 
hospitalis está documentado en la segunda mitad del siglo XI. ${ }^{80}$ Por un documento de los Libri Antiquitatum sabemos que el hospital de la catedral fue fundado en 1024, dos años después de la muerte de Goltred ${ }^{81}$,

Mir Goltred no abandonó con el ingreso en el capítulo la acumulación iniciada por su padre. Tengamos en cuenta que el ordo canonicus podía disponer (a diferencia de los ordo monasticus) de propiedad inmobiliaria, según lo establecido por las institutiones Aquisgranenses de 806. En este sentido nada impedía a Mir Goltred continuar con la política de compras de su padre. Las compras de Mir Goltred se centraron, como en el caso de su padre, en el territorio de Reixac y entre 1025 y 1055 adquirió (en ocasiones junto a sus hermanos) 39 tierras, pagando por ello un total de 761 sous. Sólo hacia 1055 se interrumpieron las compras de tierras efectuadas por Mir Goltred. El mismo año éste realizaba una donación de un gran número de bienes a favor de la canóniga de Barcelona. ${ }^{82} \mathrm{Al}$ parecer no se trataba de aquellas tierras que representaban su eventual herencia paterna, sino de aquellos bienes que había ido adquiriendo él mismo desde 1025. En cualquier caso, a partir de 1055 Mir Goltred sólo aparecerá comprando en nombre del capítulo catedralício (vice canonicorum Sce. Crucis) ${ }^{83}$. Todo parece indicar un alejamiento de los negocios seculares para dedicarse con plenitud a la vita cannonica.

11. Mir Goltred era muy joven cuando murió su padre. Con anterioridad a su muerte en 1022 debió de haber habido algún tipo de acuerdo entre la canóniga y Goltred sobre el ingreso del niño en el capítulo. Es de suponer, aunque no tengamos noticias de ello, que a raíz de este

\footnotetext{
${ }^{80} \mathrm{Cf}$., por ejemplo, ACA/C, Perg. Ramon Berenguer I, 484 (1075): se donan diez «untias $\ldots$ ad ipsa kanonicha Sce. Crucis Sancteque Eulalie et alias X concedo ad ipso ospitali et veniant in potestate Miro Goltredi».

${ }^{81}$ Donación del conde Berenguer Ramon II de diversos bienes en los territorios que rodeaban la ciudad de Barcelona: a ello se añadía una donación del obispo Umbert y de los canónigos de tres modiatas de viña ein territorio nuncupato Rixacho ... que sunt cum ipsi predicti ospitalis avere edificatas». Del hospital se dice "quod videtur esse situm intra menia prefate urbis, iusta introitum prelocute sancte sedis, subtus nostro eodem dormitorio quod est ad plagam septentrionalem et detinet se cum ipso prelocute civitatis murom. Para la historia del hospital cf. J. BAuCELls, Gènesi de la Pia Almoina de la Seu de Barcelona: els fundadors, en La pobreza y la asistencia a los pobres en la Cataluña medieval, ed. M. Riu, Barcelona, 1980-82, 1, pp. 19-22; J. W. BRodman, The Origins of Hospitallerism in Medieval Catalonis, en Iberia and the Mediterranean World of the Middle Ages, 1, ed. L. J. Simon, Leiden..., 1995, p. 294.

${ }^{82} \mathrm{ACB}$, Lib. Ant., II, 729 (1055).

${ }^{83} \mathrm{ACB}$, Lib. Ant., III, 49 (1065); 176 (1067).
} 
acuerdo Mir Goltred haya sido dotado generosamente por su padre. Por nuestra parte, sospechamos que fue a Mir al que posiblemente se le otorgó la gran masa de las propiedades paternales en un momento anterior a la redacción de la última voluntad de Goltred y como donación hereditaria pre mortem $^{84}$. Ello explicaría el hecho paradójico de que el testamento de Goltred nada disponga explícitamente acerca de lo que debió ser la mayor parte de su patrimonio y de que el mismo tampoco mencione a su hijo $\mathrm{Mir}^{85}$. Ignoramos los detalles del destino ulterior de este patrimonio. No se ha conservado un testamento de Mir Goltred. Sin embargo, podemos estar seguros que en uno $u$ otro momento las tierras que formaron el patrimonio de Goltred de Reixac pasaron a la comunidad capitular de Barcelona: de otra manera no se comprendería la inclusión de las chartas de Goltred en este inventario de derechos y propiedades que constituye el cartulario catedralício.

La acumulación de tierras realizada por Goltred durante toda su vida acabó, por lo tanto y de una u otra manera, engrosando el patrimonio capitular. Ello lleva a plantear la pregunta si este hecho no refleja sino un 'accidente' en las estrategias de acumulación y promoción campesina. La posibilidad parece plausible. No obstante, también cabría pensar en la posibilidad de que el destino final de los bienes, su integración en el patrimonio capitular, haya sido una circunstancia prevista desde un principio. La estrategia de Goltred habría sido, en este sentido, obtener mediante la compra de tierras una dotación suficiente para el hijo destinado a la 'carrera' eclesiástica. Al menos en este caso lo que se ha denominado el 'mercado de la tierra' aparece, pues, mediatizado por el interés de una promoción filial que tuvo como contrapartida la transferencia de la masa del patrimonio familiar a la catedral de Barcelona.

\footnotetext{
${ }^{84}$ LI. To Figueras, Familia i hereu a la Catalunya nord-oriental (segles X-XII), Barcelona. 1997, pp. 129-137.

${ }^{85} \mathrm{Con}$ todo, también es posible que esta parte de patrimonio haya quedado confiada a la esposa de Goltred. El testamento lega a la umulier ... terras et vineas, cultas et ermas et omni genus arborum, cubos et tonnas, vascula maiore vel minore et bestias maiores vel minores, ut in diebus vite sue teneat et possideat sine blandimento de ullumque hominem». Como condición del usufructo vitalício se establece que «nutrat filios meos et marid filias meas et suas, et si alio viro prendiderit estranea fiat». En su testamento de 1044 Ballomara legaba a su hijo Mir el directum que tenía en vida «in casas, in terras, in vineas et in arboribus», ACB, Lib. Ant., III, 645 .
} 
Cuadro 1: Las compras realizadas por Goltred

\begin{tabular}{|c|c|c|c|}
\hline años & $\begin{array}{c}\text { compras realizadas por } \\
\text { Goltred }\end{array}$ & $\begin{array}{c}\text { valor global de las } \\
\text { compras } \\
\text { (en sous })\end{array}$ & $\begin{array}{c}\text { valor medio de las } \\
\text { compras } \\
\text { (en sous })\end{array}$ \\
\hline $986-990$ & 2 & 28 & 14 \\
\hline $991-995$ & 6 & 182,5 & 30,5 \\
\hline $996-1000$ & 15 & 277,5 & 18,5 \\
\hline $1001-1005$ & 15 & 192,5 & 13 \\
\hline $1006-1010$ & 13 & 178,5 & 21 \\
\hline $1011-1015$ & 13 & 267 & 28 \\
\hline $1016-1020$ & 12 & 330,5 & 14 \\
\hline total & 76 & $1.456,5$ & 21 \\
\hline
\end{tabular}

Cuadro 2: Las compras realizadas en el territorio de Reixac

\begin{tabular}{|c|c|c|c|}
\hline años & $\begin{array}{c}\text { compras realizadas en } \\
\text { Reixac }\end{array}$ & $\begin{array}{c}\text { valor global de las } \\
\text { compras } \\
\text { (en sous) }\end{array}$ & $\begin{array}{l}\text { valor medio de las } \\
\text { compras } \\
\text { (en sous) }\end{array}$ \\
\hline $921-925$ & 1 & 10 & 10 \\
\hline $926-930$ & - & - & - \\
\hline $931-935$ & - & - & - \\
\hline $936-940$ & 1 & 13 & 13 \\
\hline $941-945$ & 1 & 5 & 5 \\
\hline $946-950$ & - & - & - \\
\hline $951-955$ & - & - & - \\
\hline $956-960$ & - & - & $=$ \\
\hline $961-965$ & - & - & - \\
\hline $966-970$ & - & - & - \\
\hline $971-975$ & - & - & - \\
\hline $976-980$ & - & - & - \\
\hline $981-985$ & 2 & 40) & 20 \\
\hline $986-990$ & 6 & 191 & 32 \\
\hline $991-995$ & 7 & 194,5 & 28 \\
\hline $996-1000$ & 24 & 412,5 & 17 \\
\hline $1001-1005$ & 21 & 238,5 & 11 \\
\hline $1006-1010$ & 22 & 298 & 14 \\
\hline $1011-1015$ & 17 & 351 & 21 \\
\hline $1016-1020$ & 13 & 330,5 & 25 \\
\hline total & 115 & 2.084 & \\
\hline
\end{tabular}


Cuadro 3: Los medios de pago de Goltred

\begin{tabular}{|c|c|c|c|c|c|c|c|}
\hline años & $\begin{array}{c}\text { compras } \\
\text { pagadas } \\
\text { en sous }\end{array}$ & $\begin{array}{c}\text { compras } \\
\text { pagadas en } \\
\text { diners } \\
\text { grossos }\end{array}$ & $\begin{array}{c}\text { compras } \\
\text { pagadas en } \\
\text { mancusos }\end{array}$ & $\begin{array}{c}\text { compras } \\
\text { pagadas en } \\
\text { uncias }\end{array}$ & $\begin{array}{c}\text { compras } \\
\text { pagadas } \\
\text { en } \\
\text { oro/plata }\end{array}$ & $\begin{array}{c}\text { compras } \\
\text { pagadas } \\
\text { en } \\
\text { especic }\end{array}$ & $\begin{array}{c}\text { compras } \\
\text { pagadas en } \\
\text { especie y } \\
\text { oro/plata }\end{array}$ \\
\hline $981-985$ & - & - & - & - & - & - & - \\
\hline $986-990$ & 2 & - & - & - & - & - & - \\
\hline $991-995$ & 5 & - & 1 & - & - & - & - \\
\hline $996-1000$ & 6 & - & 7 & - & 2 & - & - \\
\hline $1001-1005$ & 7 & - & 3 & - & 5 & - & - \\
\hline $1006-1010$ & 4 & - & 7 & - & 1 & 1 & - \\
\hline $1011-1015$ & 2 & - & 5 & 1 & 2 & 3 & - \\
\hline $1016-1020$ & 2 & 2 & 2 & 1 & 3 & 1 & 1 \\
\hline total & 28 & 2 & 25 & 2 & 13 & 5 & 1 \\
\hline
\end{tabular}

Cuadro 4: Los medios de pago en Reixac

\begin{tabular}{|c|c|c|c|c|c|c|c|}
\hline $\operatorname{años}$ & $\begin{array}{l}\text { compras } \\
\text { pagadas } \\
\text { en sous }\end{array}$ & $\begin{array}{c}\text { compras } \\
\text { pagadas } \\
\text { en diners } \\
\text { grossos }\end{array}$ & $\begin{array}{c}\text { compras } \\
\text { pagadas } \\
\text { colmom- } \\
\text { cussos }\end{array}$ & $\begin{array}{l}\text { compras } \\
\text { pagadas en } \\
\text { IIncias }\end{array}$ & $\begin{array}{c}\text { compras } \\
\text { pagadas en } \\
\text { oro/plata }\end{array}$ & $\begin{array}{c}\text { compras } \\
\text { pagadas } \\
\text { en espe- } \\
\text { cic }\end{array}$ & $\begin{array}{l}\text { compras } \\
\text { pagadas en } \\
\text { especic y } \\
\text { oro/platal }\end{array}$ \\
\hline $921-925$ & $T$ & - & - & - & - & - & - \\
\hline $926-930$ & - & - & - & - & - & - & - \\
\hline $931-935$ & - & - & - & - & - & - & - \\
\hline $936-940$ & $T$ & - & - & - & - & - & - \\
\hline $941-945$ & $T$ & - & - & - & - & - & - \\
\hline $946-950$ & - & - & - & - & - & - & - \\
\hline $951-955$ & - & - & - & - & - & - & $=$ \\
\hline $956-960$ & - & - & - & - & - & - & - \\
\hline $961-965$ & - & - & - & - & $=$ & - & - \\
\hline $966-970$ & - & - & - & - & - & - & - \\
\hline $971-975$ & - & - & - & - & - & - & - \\
\hline $976-980$ & - & - & - & - & - & - & - \\
\hline $981-985$ & 2 & - & - & - & - & - & - \\
\hline $986-990$ & 6 & - & - & - & - & - & - \\
\hline 991.995 & 6 & - & 1 & - & - & - & - \\
\hline $996-1000$ & 10 & - & T0 & - & 3 & $T$ & - \\
\hline $1001-1005$ & 7 & - & 7 & - & 5 & $T$ & $T$ \\
\hline $1006-1010$ & 5 & - & 12 & - & 3 & 2 & - \\
\hline 1011.1015 & 2 & - & 7 & 1 & 2 & 4 & $T$ \\
\hline $1016-1020$ & 2 & 2 & 2 & $T$ & 3 & 2 & $T$ \\
\hline total & 43 & 2 & 39 & 2 & 16 & 10 & 3 \\
\hline
\end{tabular}


Cuadro 5: Los pagos en oro de Goltred

\begin{tabular}{|c|c|c|c|c|}
\hline años & $\begin{array}{c}\text { valor global de las } \\
\text { compras } \\
\text { (en sous) }\end{array}$ & $\begin{array}{c}\text { valor contratado } \\
\text { en oro } \\
\text { (en mancusos) }\end{array}$ & $\begin{array}{c}\text { valor contratado } \\
\text { en oro } \\
\text { (en sous) }\end{array}$ & $\begin{array}{c}\text { proporción del } \\
\text { valor contratado } \\
\text { en oro }\end{array}$ \\
\hline $986-990$ & 28 & - & - & - \\
\hline $991-995$ & 182,5 & 1,5 & 10,5 & $6 \%$ \\
\hline $996-1000$ & 277,5 & 20,5 & 143,5 & $52 \%$ \\
\hline $1001-1005$ & 192,5 & 20,5 & 143,5 & $75 \%$ \\
\hline $1006-1010$ & 178,5 & 21,5 & 150,5 & $84 \%$ \\
\hline $1011-1015$ & 267 & 36,5 & 256,5 & $96 \%$ \\
\hline $1016-1020$ & 330,5 & 37 & 261 & $79 \%$ \\
\hline total & 1.456 .5 & 137,5 & 965,5 & \\
\hline
\end{tabular}

Cuadro 6: Los pagos en oro en Reixac

\begin{tabular}{|c|c|c|c|c|}
\hline años & $\begin{array}{l}\text { valor global de } \\
\text { las compras } \\
\text { (en sous) }\end{array}$ & $\begin{array}{l}\text { valor contratado } \\
\text { en oro } \\
\text { (en mancusos) }\end{array}$ & $\begin{array}{l}\text { valor contratado } \\
\text { en oro } \\
\text { (en sous) }\end{array}$ & $\begin{array}{l}\text { proporción del } \\
\text { valor contratado } \\
\text { en oro }\end{array}$ \\
\hline $921-925$ & 10 & - & - & - \\
\hline $926-930$ & - & - & - & - \\
\hline $931-935$ & - & - & - & - \\
\hline $936-940$ & 13 & - & - & - \\
\hline $941-945$ & 5 & - & - & - \\
\hline $946-950$ & - & - & - & - \\
\hline $951-955$ & - & - & - & - \\
\hline $956-960$ & - & - & - & - \\
\hline $961-965$ & - & - & - & - \\
\hline $966-970$ & - & - & - & - \\
\hline $971-975$ & - & - & - & - \\
\hline $976-980$ & - & - & - & - \\
\hline $981-985$ & 40) & - & - & - \\
\hline $986-990$ & 191 & $\begin{array}{lll}- & - \\
0\end{array}$ & - & - \\
\hline $991-995$ & 194,5 & 1,5 & 10,5 & $5 \%$ \\
\hline $996-1000$ & 412,5 & 32,5 & 227,5 & $55 \%$ \\
\hline $1001-1005$ & 238,5 & 21,5 & 143,5 & $60 \%$ \\
\hline $1006-1010$ & 298 & 37 & 259 & $87 \%$ \\
\hline $1011-1015$ & 351 & 48,5 & 340,5 & $97 \%$ \\
\hline $1016-1020$ & 330,5 & 37 & 261 & $79 \%$ \\
\hline total & 2.084 & 178 & 1.242 & \\
\hline
\end{tabular}


Cuadro 7: Distribución de la tierra en Reixac y Montpeytà (980-1020)

\begin{tabular}{|l|c|c|c|c|}
\hline & $\begin{array}{l}\text { número de parcelas cita- } \\
\text { das en las affrontationes }\end{array}$ & \multicolumn{2}{|c|}{ porcentajes } \\
\hline & Reixac & Montpeytà & Reixac & Montpeytà \\
\hline tierras de la Iglesia y de clérigos & 118 & 67 & $20 \%$ & $15 \%$ \\
\hline tierras de magnates & 3 & 5 & $1 \%$ & $1 \%$ \\
\hline tierras de campesinos & 460 & 370 & $79 \%$ & $84 \%$ \\
\hline total & 581 & 442 & & \\
\hline
\end{tabular}

Cuadro 8: Las propiedades campesinas en Reixac y Montpeytà (980-1020)

\begin{tabular}{|l|c|c|c|c|}
\hline & propietarios campesinos & \multicolumn{2}{c|}{ porcentajes } \\
\hline & Reixac & Montpeytà & Reixac & Montpeytà \\
\hline $1-5$ affrontationes & 99 & 82 & $85 \%$ & $83 \%$ \\
\hline $6-10$ affrontationes & 7 & 10 & $6 \%$ & $10 \%$ \\
\hline $11-15$ affrontationes & 6 & 2 & $5 \%$ & $2 \%$ \\
\hline $16-20$ affrontationes & 3 & 2 & $3 \%$ & $2 \%$ \\
\hline $21-25$ affrontationes & - & 2 & - & $2 \%$ \\
\hline $26-30$ affrontationes & - & 1 & - & $1 \%$ \\
\hline$>30$ affrontationes & 1 & - & $1 \%$ & - \\
\hline total & 116 & 99 & & \\
\hline
\end{tabular}




\section{RÉSUMÉ}

L'article a pour but d'étudier la circulation des terres, les ventes et les achats des biens fonciers, ainsi que les effets de cette circulation sur la société paysanne catalane de la fin du Xe au début du XIe siècle. Le sujet est abordé a partir d'un cas concret, le paysan Goltred de Reixac del Vallès, un cas particulierement bien etayé grâce aux nombreux documents conservés aux archives capitulaires de Barcelone.

\section{SUMMARY}

The paper deals with the transactions related to the buying and selling of estates, and the social and economic effects this had on catalan peasant society of the late Xth and the early XIth century. The subject phocuses on a specific case study, that of Goltred, a peasant of Reixac del Vallès, a particularly well documented case since there is an abundance of documentary evidence preserved in the archives of the cathedral chapter of Barcelona. 